Introduction: Cancer located in the oesophagus and gastroesophageal junction is a complex clinical problem and the results of its treatment still remain unsatisfactory. The objective of the study was the clinical analysis of a group of patients with cancer of the oesophagus or gastroesophageal junction, who received combined medical and surgical treatment.

Material and methods: The analysis was performed on a group of 128 patients with the diagnosis of oesophageal cancer or cancer of the gastroesophageal junction. Analysis of medical records and follow-up examinations were used in the research procedure.

Results: From among 128 patients with a diagnosis of oesophageal or gastroesophageal junction cancer, 50 (38.5\%) received surgical resections. The surgery most frequently performed $(n=15)$ was sub-total oesophageal resection according to Akiyama procedure by right-sided thoracotomy (oesophageal anastomosis in the neck). The largest group were patients $(n=26)$ with stage $\mathrm{T}_{3} \mathrm{~N}_{1} \mathrm{M}_{0}$ of advancement of the disease. In all cases of cancer located in the lower third of the oesophagus, an adenocarcinoma pattern was diagnosed in the histopathological examination, whereas in the case of cancers located in the middle third and upper third of the thoracic oesophagus a carcinoma planoepitheliale pattern was seen. Anastomotic leaks occurred in seven patients (14\%). Six patients died during the post-operative period (12\%). The mean survival time in the group of analysed patients was two years.

Conclusions: Cancer of the oesophagus or gastroesophageal junction is associated with low resectability, high risk of complications after surgery, and poor oncologic outcome. It is necessary to seek new methods of treatment.

Key words: oesophagectomy, oesophageal cancer, surgical treatment.

Contemp Oncol (Pozn) 2014; 18 DOI: $10.5114 /$ wo.2014.43494

\section{Cancer of the oesophagus and gastroesophageal junction - a difficult clinical problem}

\author{
Stanisław Głuszek ${ }^{1,2}$, Marta Kot ${ }^{2}$, Bartłomiej Kotucha², Renata Stępieńn ${ }^{1}$ \\ Dorota Koziet ${ }^{1}$ \\ ${ }^{1}$ Faculty of Health Sciences, Jan Kochanowski University, Kielce, Poland \\ ${ }^{2}$ Clinical Ward of General, Oncological, and Endocrine Surgery of the Voivodeship \\ Hospital in Kielce, Poland
}

\section{Introduction}

According to statistical data from the database GLOBOCAN 2008, annually 482,300 patients worldwide contract cancer, of whom 406,800 die [1]. In Poland, in accordance with the data presented in the National Cancer Register, in 2010, 929 cases of this type of cancer were noted in males $(1.41 \%$ of cases of malignant cancer), and 243 in females (0.3\%). Standardised morbidity rates for males and females were 3.3 and 0.6 , respectively. The highest morbidity risk concerned both genders within the age interval from 55-64 years. During the period analysed, in Poland, 1,106 deaths due to oesophageal cancer were noted among males $(2.13 \%$ of deaths due to malignant cancer) and 290 in females (0.71\%), and the standardised death rates were 3.93 and 0.67 , respectively $[2,3]$. Thus, Poland is among the countries with relatively low morbidity and mortality due to oesophageal cancer. However, considering the low standardised rate of five-year survival of patients with this type of cancer (Poland - 3.2; worldwide - 9.8) [1], it is necessary to seek an optimum technique of treatment $[4,5]$. The incidence of oesophageal adenocarcinoma is rapidly increasing, while that concerning squamous carcinoma remains unchanged [6].

Oesophagectomy remains the standard surgical treatment of oesophageal cancer. The evaluation of the degree of clinical advancement during the pre-operative period is imprecise; hence, $\mathrm{R} 1$ resection is performed in $25 \%$ of patients, and the five-year survival rate rarely reaches $40 \%$ [7]. Cancer of the oesophagus still constitutes a complex clinical problem, and the outcomes of its treatment - both surgical and combined - are still unsatisfactory. Oesophageal resection procedures are still associated with considerable morbidity and mortality rates. In recent years, a decrease has been observed in post-operative mortality; nevertheless, the risk of surgical complications still remains high. Surgical complications occur in $10-27 \%$ of patients who undergo surgical procedures. The prognosis is still bad in patients who receive resection. Less than $40 \%$ of patients are qualified for resection [8].

The surgical strategy, to a large extent, is determined by the location and histological type of cancer. While considering the possibilities of surgical treatment of oesophageal or gastroesophageal junction cancer the following surgical techniques may be taken into account: total gastrectomy and resection of the lower section of the oesophagus; resection of the upper section of the stomach and lower section of the oesophagus in cases of gastroesophageal junction cancer, together with an adequate minimum and maximum margin and lymphadenectomy; in the case of cancer concerning the middle and upper thoracic oesophagus - sub-total oesophageal resection, leaving the neck part of the oesophagus unexcised and with implanted oesophageal anastomosis modelled from the stomach, large intestine, or jejunum, according to 
the technical and anatomical possibilities, preserving the above-mentioned principles of oncological surgery [8].

Despite the development of molecular, endoscopic, surgical, and radiotherapeutic techniques, as well as an increase in the effectiveness of chemotherapy, cancers of the oesophagus or gastroesophageal junction still remain a very difficult clinical problem. The special biology of this cancer determines unfavourable prognosis $[4,7,8,10,11]$. Hence, analysis of the subsequent clinical experiments may bring about important conclusions and contribute to the improvement of the diagnostic and treatment procedure.

The objective of the study was an analysis of a group of patients with cancer of the oesophagus or gastroesophageal junction who received combined medical and surgical treatment.

\section{Material and methods}

The analysis was carried out on a group of 128 patients with a diagnosis of cancer of the oesophagus or gastroesophageal junction (Type I and II according to the Siewert classification), with particular consideration of those who had undergone resection procedures with intent to cure. Mean age at onset of the disease was assessed, as well as risk factors of the development of cancer, type of surgery performed, combined treatment, stage of advancement according to TNM staging system, histological type of cancer, post-operative complications (anastomotic leaks), post-operative mortality rate, and the mean survival time. During the diagnostic process all patients were evaluated from the aspect of general condition, cardiovascular and respiratory systems, renal function, and the coagulation system. In each patient, endoscopy was performed, and considerations were based on the results of histopathological examinations of material collected during endoscopy. The basic imaging techniques were as follows: CT of the abdomen, radiography of the chest, and abdominal ultrasound (USG). In addition, a battery of morphological and biochemical tests were performed.

\section{Results}

In the group of 128 patients with the diagnosis of cancer of the oesophagus or gastroesophageal junction, 50 patients received resection procedures (38.5\%) - 37 males and 13 females. Mean age at onset of the disease in this group was 59 years (38-82); in males -59.7 years (47-82), and in females -57.4 years (38-74). As many as 35 of them were smokers, and in 15 a history of alcohol consumption was additionally established. One female patient had previously undergone radiotherapy in the chest region due to bilateral breast cancer. The mean duration of hospitalisation in the surgical ward after the surgery was 14.47 (4-25) days. In eight patients, resection of the upper part of the stomach was performed and removal of the lower oesophagus with gastroesophageal 'end-to-end' anastomosis, without thoracotomy; in eight patients - upper gastric resection and resection of the lower part of the esophagus with gastroesophaegal 'end-to-side' anastomosis via a left thoracotomy; in 11 patients - total gastric resection and resection of the lower thoracic oesophagus with gastroesophageal anastomosis by the method of Roux-en-Y gastric bypass, in the mediastinum, without thoracotomy; in eight patients - total gastrectomy and resection of the lower half of the thoracic oesophagus with gastroesophageal Roux-en-Y anastomosis via a left thoracotomy; and in 15 - sub-total resection of the oesophagus using the Akiyama method via a right thoracotomy (gastroesophageal anastomosis in the neck). Table 1 presents detailed results.

The largest group $(n=24)$ were patients with stage T3N1MO of advancement. In all cases of cancer located in the lower third of the oesophagus, an adenocarcinoma pattern was observed $(n=34)$, while in the cases of cancers located in the middle third and upper third of the thoracic oesophagus a carcinoma planoepitheliale pattern was seen $(n=15)$. In a single case $(n=1)$ with a change in the lower oesophagus, so-called Barret's oesophagus with high-grade dysplasia was diagnosed. Table 3 presents the analysed data.

The most frequent post-operative complications were as follows: anastomotic leak ( $n=7 ; 14 \%)$, acute respiratory distress syndrome (ARDS) $(n=2 ; 4 \%)$, and sudden cardiac arrest (SCA) ( $n=2 ; 4 \%)$. Anastomotic leak occurred in three patients after surgery performed by the Akiyama method, two - after resection of the upper part of the oesophagus and resection of the upper part of the stomach with thoracotomy, and two - after gastrectomy with thora-

Table 1. Types of resection procedures performed in the examined group of patients with cancer of the oesophagus and gastroesophageal junction

\begin{tabular}{lcc}
\hline Types of surgical procedures (resection) & Study group & \% \\
$\begin{array}{l}\text { Upper gastric resection + resection of lower oesophagus ('end-to-end' anastomosis without } \\
\text { thoracotomy) }\end{array}$ & 8 & 16 \\
$\begin{array}{l}\text { Upper gastric resection + resection of lower oesophagus 'end-to-side' anastomosis with } \\
\text { thoracotomy (by left-sided thoracotomy) }\end{array}$ & 8 & 16 \\
$\begin{array}{l}\text { Total gastrectomy and resection of lower half of the thoracic oesophagus (gastroesophageal Roux- } \\
\text { en-Y anastomosis by left-sided thoracotomy) }\end{array}$ & 8 & 16 \\
$\begin{array}{l}\text { Total gastrectomy and resection of lower half of thoracic oesophagus (gastroesophageal Roux-en-Y } \\
\text { anastomosis in the mediastinum without thoracotomy) }\end{array}$ & 11 \\
$\begin{array}{l}\text { Sub-total resection of oesophagus using the Akiyama method (via right-sided thoracotomy, } \\
\text { gastroesophageal anastomosis in the neck) }\end{array}$ & 15 \\
Total & 50 & 30 \\
\end{tabular}


cotomy. Leaks were treated conservatively, with the use of an effective drainage and parenteral nutrition, and in two cases - by endoscopic prosthetic treatment of the leaks. In two cases, surgical treatment was applied. During the post-operative period six deaths were noted (12\%), which concerned patients at advanced age or those with a high degree of advancement of cancer: one (2\%) - after Akiyama procedure, four (8\%) - after gastrectomy, resection of the lower oesophagus and gastroesophageal anastomosis in the chest, and one (2\%) - after gastric resection, resection of the lower part of the oesophagus and gastroesophageal anastomosis without thoracotomy. Table 3 presents a detailed assessment of the stage of clinical advancement of cancer of the oesophagus and gastroesophageal junction, with consideration of the frequency of post-operative complications.

A statistically significant relationship was observed $\left(\chi^{2}=3.9 ; p=0.04631\right)$ between the stage of clinical advancement of oesophageal cancer according to the TNM staging system and post-operative mortality. It was found that the higher the stage of clinical advancement of cancer, the higher the post-operative mortality risk. The most frequent post-operative complications were anastomotic leak, ARDS, and SCA. The mean survival time in the group of patients in the study was two years. The patient with the longest observation (14 years) is after Akiyama procedure and who, at the time of surgery, was aged 38 years, and was a habitual tobacco smoker. The patient had undergone pre-operative chemoradiotherapy. The stage of clinical advancement of oesophageal cancer was evaluated as T1NOMO, in pre-operative histological examination and carcinoma planoepitheliale was diagnosed. However, in post-operative material no cancer pattern was found.
Table 2. Results of histopathological evaluation of cancer of the oesophagus and gastroesophageal junction in the group of patients in the study

\begin{tabular}{lcc} 
Results of histopathological examination & \multicolumn{3}{c}{ Study group } \\
& $n$ & $\%$ \\
Adenocarcinoma & 34 & 68 \\
Carcinoma planoepitheliale & 15 & 30 \\
Barrett's oesophagus with high-grade dysplasia & 1 & 2 \\
Total & 50 & 100
\end{tabular}

\section{Discussion}

The treatment of cancer of the oesophagus still remains a challenge for surgeons, due to hindered anatomical access, and the extent of surgical procedure in the region of the neck, chest, and abdominal cavity, as well as the necessity for simultaneous reconstruction of the resected part of the gastrointestinal tract. The development of endoscopic, surgical, and radiotherapeutic techniques, as well as progress in chemotherapy, has not significantly improved the outcomes of treatment, which are still unsatisfactory. Due to the lack of an epidemiological and economic justification, no screening studies for oesophageal cancer are being conducted in Europe [5, 8, 11-14].

The organ that is most often used for the reconstruction of continuity of the gastrointestinal tract is the stomach. In some cases, when it cannot be used, the reconstruction of the gastrointestinal tract is performed using a pedicled segment of the large intestine. Compared to the reconstruction with the use of the stomach, the translocation of the colon requires a longer surgical time, and

Table 3. Evaluation of the stage of clinical advancement of cancer of the oesophagus and gastroesophageal junction, and frequency of post-operative complications

\begin{tabular}{|c|c|c|c|c|c|c|c|c|}
\hline \multicolumn{4}{|c|}{ Evaluation of clinical advancement of cancer } & \multicolumn{4}{|c|}{ Complications } & \multirow[b]{3}{*}{ Feature } \\
\hline \multirow[t]{2}{*}{ Grade } & \multirow{2}{*}{$\begin{array}{l}\text { Feature } \\
\text { TNM }\end{array}$} & \multirow[t]{2}{*}{$n$} & \multirow[t]{2}{*}{$\%$} & \multicolumn{2}{|c|}{ Anastomotic leak } & \multicolumn{2}{|c|}{ Death } & \\
\hline & & & & $n$ & $\%$ & $n$ & $\%$ & \\
\hline 0 & $\mathrm{~T}_{\text {is }} \mathrm{N}_{0} \mathrm{M}_{0}$ & 1 & 2 & 0 & 0 & 0 & 0 & - \\
\hline \multirow[t]{2}{*}{ । } & $\mathrm{T}_{1} \mathrm{~N}_{0} \mathrm{M}_{0}$ & 4 & 8 & 1 & 2 & 0 & 0 & - \\
\hline & $\mathrm{T}_{2} \mathrm{~N}_{0} \mathrm{M}_{0}$ & 3 & 6 & 0 & 0 & 0 & 0 & - \\
\hline \multirow[t]{2}{*}{$\|$} & $\mathrm{T}_{3} \mathrm{~N}_{0} \mathrm{M}_{0}$ & 5 & 10 & 0 & 0 & 0 & 0 & - \\
\hline & $\mathrm{T}_{2} \mathrm{~N}_{1} \mathrm{M}_{0}$ & 3 & 6 & 0 & 0 & 1 & 2 & $\begin{array}{c}\text { I. } 56,0 \text {, resection } R_{2} \text { (infiltration on the spleen, } \\
\text { lymph nodes in celiac artery region); in post- } \\
\text { operative course - chylothorax }\end{array}$ \\
\hline \multirow[t]{7}{*}{ III } & $\mathrm{T}_{4} \mathrm{~N}_{0} \mathrm{M}_{0}$ & 2 & 4 & 2 & 4 & 0 & 0 & - \\
\hline & & & & & & & & 75 ı., ô, ARDS \\
\hline & & & & & & & & 68 I., ठ̃, ARDS \\
\hline & $\mathrm{T}_{3} \mathrm{~N}_{1} \mathrm{M}_{0}$ & 26 & 52 & 3 & 6 & 4 & 8 & 64 I., ô, SCA \\
\hline & & & & & & & & 49 l., + , anastomotic leak \\
\hline & $\mathrm{T}_{3} \mathrm{~N}_{3} \mathrm{M}_{0}$ & 1 & 2 & 0 & 0 & 0 & 0 & - \\
\hline & $\mathrm{T}_{4} \mathrm{~N}_{3} \mathrm{M}_{0}$ & 2 & 4 & 0 & 0 & 1 & 2 & 82 l., $, L_{1} \bigvee_{1} R_{0}, N Z K$ \\
\hline \multirow[t]{2}{*}{ IV } & $\mathrm{T}_{3} \mathrm{~N}_{0} \mathrm{M}_{1}$ & 2 & 4 & 0 & 0 & 0 & 0 & - \\
\hline & $\mathrm{T}_{2} \mathrm{~N}_{2} \mathrm{M}_{1}$ & 1 & 2 & 1 & 2 & 0 & 0 & - \\
\hline \multicolumn{2}{|c|}{ Total } & 50 & 100 & 7 & 14 & 6 & 12 & - \\
\hline
\end{tabular}


obliges, among other things, mobilisation of the colon, and additional anastomoses that increase surgical stress and the risk of complications. Hamai et al. [15] presented material concerning 40 patients who received oesophagectomy with translocation of the colon and ileum to the chest and neck, selected from among 436 patients who had undergone surgical treatment due to oesophageal cancer, and in the majority of whom other techniques of reconstruction of the gastrointestinal tract were applied (most frequently using transplant from the stomach). The mean duration of surgery was 450 minutes. Eighteen (45\%) patients had various complications: in seven (17.5\%) there was anastomotic leak (in the presented study - 14\%), and in two (5\%) - necrosis of the reconstruction. Thirty-day mortality was $0 \%$, while 90 -day mortality was $2.5 \%$, and 1,3 , and 5 -year survivals were $80 \%, 66 \%$, and $66 \%$, respectively.

In the studies by Camerlo et al. [16] the results of treatment of cancer of the oesophagus or gastroesophageal junction were compared in three groups of patients. The first group were patients aged less than 70 years, in whom neoadjuvant therapy had been applied; the second group were patients aged over 70, who had not undergone neoadjuvant therapy; and the third group were patients aged over 70, who received neoadjuvant therapy. No differences in post-operative mortality were observed between the individual groups ( $6 \%$ vs. $6 \%$ vs. $10 \%, p=0.50$ ). The durations of survival and quality of life did not differ either. The researchers emphasised the importance of surgical treatment of patients of advanced age with the diagnosis of the disease and adequately evaluated stage of its advancement.

It should be stressed that the discussion concerning neoadjuvant chemoradiotherapy in oesophageal cancer has been ongoing for years. In the majority of randomised studies, no advantages were confirmed resulting from this therapy, and trials were criticised for inadequate methodology and small size of the samples of patients. However, meta-analyses suggest benefits from neoadjuvant chemoradiotherapy, although they are often achieved at the cost of high morbidity and mortality rates $[17,18]$.

Discrepancies in the evaluations of the effectiveness of neoadjuvant chemoradiotherapy have become an inspiration for van Hagen et al. [18] to plan multi-centre, randomised studies comparing the outcomes of treatment in a group of 178 patients who received neoadjuvant chemoradiotherapy in combination with antegrade surgical procedure, with a group of 188 patients treated only by surgery. Ultimately, into the studies conducted from March 2004 to December 2008, 366 patients were included: 275 patients with adenocarcinoma (75\%), 84 (23\%) with squamous cancer, and 7 (2\%) with undifferentiated large cell carcinoma. In chemotherapy, carboplatin and paclitaxel were administered for 5 weeks, as well as radiotherapy - 41.4 Gy in 23 fractions, 5 days per week. After the neoadjuvant therapy, surgical treatment was applied. RO resections were performed in $92 \%$ of the patients who had previously undergone radiochemotherapy, compared with $69 \%$ in the group which received only surgical treatment. A pathological complete response was observed in 29\% of patients who received chemoradiotherapy. Post-oper- ative complications were similar in both groups, and the hospital mortality rate was $4 \%$. Median survival was 49.4 months in the group after chemoradiotherapy (5-year survival $-47 \%$ ), compared with 24 months in the group of patients who received surgical treatment only (5-year survival $-34 \%)$. The reports by Platz et al. [19] also confirm the effect of the above-mentioned neoadjuvant three-modality treatment (carboplatin/paclitaxel and radiotherapy). Thus, pre-operative chemoradiotherapy improves the survival outcomes in patients with potentially operable cancer of the oesophagus or gastroesophageal junction.

The results of analyses performed in the group of patients in this study are close to those reported in literature. It is noteworthy that, similar to the majority of malignant cancers of the gastrointestinal tract, only an early diagnosis of oesophageal cancer offers a chance for recovery. From among a group of 128 patients, a considerable number were admitted to hospital through an Emergency Department, with symptoms of long-lasting dysphagia and malnutrition. Such a clinical condition predisposes increased post-operative morbidity and mortality rates. After performing diagnostic examinations, and an evaluation of the stage of advancement and malignancy of cancer, only $40 \%$ could be qualified for resection (similar to that seen in Swedish studies [8]). Similar to a considerable part of analyses reported in literature, stage T2-T3 of advancement of tumour and the presence of metastases to the lymph nodes considerably worsen the prognosis. Due to the features of the spread of cancer of the oesophagus and gastroesophageal junction, the disease is incurable, so palliative treatment is applied which allows the intake of food, liquids, and even swallowing saliva (endoscopic oesophageal prosthesis, very rarely oesophageal bypass, gastrostomy, or feeding jejunostomy), analgesic treatment, and other palliative care procedures.

Both surgical treatment as an independent therapeutic method and that preceded by neoadjuvant chemoradiotherapy are very complex procedures associated with a high risk of complications (10-27\% according to Rutegard [8] and 50\% according to other researchers). Mortality is on the level of several to more than a dozen per cent, according to the patients' general condition, stage of advancement of cancer, as well as the experience of the surgical and anaesthesia team [8].

While seeking methods of improvement of the outcomes of treatment of cancer of the oesophagus and gastroesophageal junction, during the period of induction of anaesthesia, Nishiyama et al. [20] applied sivelestat as a neutrophil elastase inhibitor, in order to reduce the intensity and shorten the duration of SIRS. No differences in blood oxygenation level were observed between the study and control groups; however, a significant effect of sivelestat on the decrease in the C-reactive protein (CRP) level was noted in the study group. Patients who received sivelestat were hospitalised for a shorter time, and more rapidly regained psycho-physical efficacy, compared to those from the control group. Five-year survivals were 83\% and $73 \%$, respectively, the difference being statistically insignificant. It is noteworthy that no significant differences were found in the frequency of surgical and respiratory 
post-operative complications, and the duration of respirator treatment was similar (34-50 hours). Finally, it can be presumed that the use of sivelestat may exert a beneficial effect on prognosis.

The scope of problems concerning improvement in the outcomes of treatment of cancer of the oesophagus and gastroesophageal junction covers the results of surgical treatment and its complications. The risk of complications in the form of oesophageal anastomotic leaks may be related with the technique of its performance. Nederlof et al. [21] compared two equal-sized groups (64 patients each): in one group, single-layer 'end-to-end' anastomosis in the neck was performed manually; and in the other group, end-to-side esophagogastrostomy was performed. Anastomotic leak occurred in $41 \%$ of patients after 'end-to-side' anastomosis, compared with $22 \%$ in the group of patients who had received 'end-to-end' anastomosis. Also, in this group, pulmonary complications occurred more frequently and the patients stayed in hospital for a longer time. Our experience slightly differs from the above-presented opinion; we observed fewer leaks and, in most cases, anastomoses were performed 'end-to-side', both in the regions of the neck and chest. Nederlof et al. [21], in a group of patients with 'end-to-end' anastomosis, strictures were more frequently observed (40\% vs. $18 \%$ ). Interesting modifications are currently being developed aimed at reducing the risk of anastomotic leakage. Dai et al. [22] proposed wrapping the pedicle omental flap around the esophagogastric anastomotic site. This enables a decrease in the risk of leakage down to $1 \%$, and that of strictures to $6 \%$.

The fundamental precondition for reducing the risk of anastomotic leakage is the proper vascularisation and lack of tension on the suture line. In our experience, 'end-toside' anastomosis provides better conditions for vascularisation and creation of the wrapping of the pedicle omental flap around the esophagogastric anastomotic site, unless perioperative conditions do not allow it. The treatment of leaks is very difficult. At present, self-expandable stents are applied, which are inserted by endoscopic method, and after 6-8 weeks their efficacy is on the level of approximately $85 \%$ [23]. In the presented study, effectiveness of self-expandable stents in the analysed group of patients was also observed.

In conclusion, the treatment of cancer of the oesophagus and gastroesophageal junction still remains among the most difficult oncological problems, associated with a high risk of complications. The presented clinical data confirm the complexity of the problem of surgical treatment of oesophageal cancer; hence, it is necessary to continue studies and to search for methods of improvement of the outcomes of treatment of this cancer. In each case of cancer of the oesophagus and gastroesophageal junction, neoadjuvant chemoradiotherapy should be considered.

The authors declare no conflict of interest.

\section{References}

1. GLOBOCAN 2008 (IRAC) Section Of Cancer Information (globocan. irac.fr/30.06.2013)

2. Wojciechowska U, Didkowska J, Zatoński W. In: Nowotwory złośliwe w Polsce w 2010 roku. Krajowy Rejestr Nowotworów. Centrum Onkologii Instytut im. Marii Skłodowskiej-Curie, Warszawa 2012; 52-83.

3. Wojciechowska U, Didkowska J. Nowotwory w Polsce w 2012 roku. Nowotwory 2013; 63: 197-216.

4. Skoczylas T, Wallner G. Chirurgia przełyku. In: Przegląd piśmiennictwa chirurgicznego. Dziki A (ed.). Wyd. Fundacja Polski Przegląd Chirurgiczny, Warszawa 2013. T. XX; 66-72.

5. Guzel Z. Zaawansowany rak przełyku i połączenia przełykowo-żołądkowego. Możliwości i wyniki zastosowania współczesnych metod terapeutycznych. Gastroenterol Klin 2011; 1: 17-35.

6. Szumiło J. Epidemiologia i czynniki ryzyka rozwoju raka płaskonabłonkowego przełyku. Pol Merk Lek 2009; 15: 82-5.

7. Kelsen DP, Ginsberg R, Pajak TF, et al. Chemotherapy followed by surgery compared with surgery alone for localized esophageal cancer. N Engl J Med 1998; 339: 1979-84.

8. Rutegård M, Lagergren P, Rouvelas I, Mason R, Lagergren J. Surgical complications and long-term survival after esophagectomy for cancer in a nationwide Swedish cohort study. Eur J Surg Oncol 2012; 38: 555-61.

9. Wójcik J, Grodzki T, Kubisa B, et al. Synchronus esophageal and lung cancer treated by one - stage esophagectomy and upper right lebectomy. Kardiochirur Torakochir Pol 2012; 1: 63-5.

10. Yin D, Zhang H, Wang Y, et al. Study on the relationship between TagSNPs and halotype of hCHK2 and esophageal cancer in Kazakh and Han in Xinjiang. Wspolczesna Onkol 2012; 16: 407-12.

11. Kim K, Park JS, Seo H. Early outcomes of video-assisted thoracic surgery (VATS) Ivor Lewis operation for esophageal squamous cell carcinoma: the extracorporeal anastomosis technique. Surg Laparosc Endosc Percutan Tech 2013; 3: 303-8.

12. Low DE. Evolution in surgical management of oesophageal cancer. Dig Dis 2013; 1: 21-9.

13. Kato H, Nakajima M. Treatments for esophageal cancer: a review. Gen Thora Cardiovasc Surg 2013; 61: 330-5.

14. Lewiński A, Juraszek D, Hładoń A, Lekstan A, Olakowski M, Lampe P. Resekcja gruczolakoraka przełyku i wpustu techniką przezrozworową z użyciem toru wizyjnego laparoskopu. Postępy Nauk Med 2011; 1: 11-5.

15. Hamai Y, Hihara J, Emi M, Aoki Y, Okada M. Esophageal reconstruction using the terminal ileum and right colon in esophageal cancer surgery. Surg Today 2012; 42: 342-50.

16. Camerlo A, D'Journo XB, Ouattara M, Trousse D, Doddoli C, Thomas PA. Adenocarcinoma of the esophagus and esophagogastric junction in patients older than 70 years: results of neoadiuvant radiochemioterapy followed by transthoracic esophagectomy. J Vasc Surg 2012; 149: e203-10.

17. Pöttgen C, Stuschke M. Radiotherapy versus surgery within multimodality protocols for esophageal cancer - a meta-analysis of the randomized trials. Cancer Treat Rev 2012; 6: 599-604.

18. van Hagen P, Hulshof MC, van Lanschot JJ, et al. Preoperative chemoradiotherapy for esophageal or junctional cancer. N Engl J Med 2012; 366: 2074-84.

19. Platz TA, Nurkin SJ, Fong MK, et al. Neoadjuvant chemoradiotherapy for esophageal/gastroesophageal carcinoma. J Gastrointest Oncol 2013; 2: 137-43.

20. Nishiyama J, Matsuda M, Ando S, Hirasawa M, Suzuki T, Makuuchi $H$. The effects of early administration of sivelestat sodium, a selective neutrophil elastase inhibitor, on the postoperative course after radical surgery for esophageal cancer. Surg Today 2012; 42: 659-65.

21. Nederlof N, Tilanus HW, Tran TC, Hop WC, Wijnhoven BP, de Jonge J. End-to-end versus to-side esophagogastrostomy after esophageal cancer resection. A prospective randomized study. Ann Surg 2011; 254: 226-33.

22. Dai JG, Zhang ZY, Min JX, Huang XB, Wang JS. Wrapping of the omental pedicle Flap around esophagogastric anastomosis after esophagectomy for esophageal cancer. Surgery 2011; 149: 404-10. 
23. van Boeckel PG, Sijbring A, Vleggaar FP, Siersema PD. Systematic review: temporary stent placement for benign rupture or anastomotic leak of the esophagus. Aliment Pharmacol Ther 2011; 33: 1292-301.

\section{Address for correspondence}

Stanisław Głuszek

Jan Kochanowski University

Faculty of Health Sciences

Al. IX Wieków Kielc 19

25-317 Kielce, Poland

e-mail: sgluszek@wp.pl

Submitted: 21.10 .2013

Accepted: 11.04 .2014 